\title{
Factor VII light chain-targeted lidamycin targets tissue factor- overexpressing tumor cells for cancer therapy
}

\author{
QING ZHANG ${ }^{1,3^{*}}$, XIU-JUN LIU ${ }^{2 *}$, LIAN HU ${ }^{1}$, DONG-SHENG LIAO ${ }^{1}$, \\ YAN-BO ZHENG ${ }^{2}$, YONG-SU ZHEN ${ }^{2}$ and XU SONG ${ }^{1}$ \\ ${ }^{1}$ Center for Functional Genomics and Bioinformatics, College of Life Science, Sichuan University, Chengdu, \\ Sichuan 610064; ${ }^{2}$ Institute of Medicinal Biotechnology, Chinese Academy of Medical Sciences and \\ Perking Union Medical College, Beijing 100050; ${ }^{3}$ Jiangsu Key Laboratory of Biological \\ Cancer Therapy, Xuzhou Medical College, Xuzhou 221002, P.R. China
}

Received August 28, 2011; Accepted October 4, 2011

DOI: $10.3892 / \mathrm{ijmm} .2011 .848$

\begin{abstract}
The overexpression of tissue factor (TF) observed in numerous cancer cells and clinical samples of human cancers make TF an ideal target for cancer therapy. Here, we report an energized fusion protein, hlFVII-LDP-AE, which can be used for cancer therapy and is composed of a human Factor VII light chain (hlFVII) conjugated to the cytotoxic antibiotic lidamycin (LDM, LDP-AE). hlFVII-LDP-AE binds with specificity to TF expressed on tumor cells, resulting in internalization of the fusion protein and cytotoxicity induced by the LDM domain. The potential efficacy of hlFVII-LDP-AE for cancer therapy was examined in vitro by 3-(4,5-dimethylthiazol-2-yl)-2,5-diphenyltetrazolium bromide (MTT) assays and in vivo with a BALB/c nude mouse xenograft model of the human lung cancer line NCI-H292. hlFVII-LDP-AE caused chromatin condensation and cleavage of genomic DNA in NCI-H292 cells. In the MTT assays, the $\mathrm{IC}_{50}$ value of hlFVII- LDP-AE was $0.19 \mathrm{nM}$. In the in vivo tests, after two intravenous injections of hlFVIILDP-AE at a dose of $0.6 \mathrm{mg} / \mathrm{kg}$, the growth rate of the lung tumor xenograft was reduced to $15 \%$ of the control rate, and there was no excessive loss of body weight and inflammatory response in the mice. These findings suggest that hlFVII-LDP$\mathrm{AE}$ is efficacious and tolerated in the mouse model of NCI-H292 human lung cancer examined and could have broad clinical applicability for treating cancer patients.
\end{abstract}

\section{Introduction}

An important aim of cancer research is developing a cytotoxic agent that can target tumors and not normal tissues (1-3),

Correspondence to: Dr Xu Song, Center for Functional Genomics and Bioinformatics, College of Life Science, Sichuan University, Chengdu, Sichuan 610064, P.R. China

E-mail: xusong@scu.edu.cn

*Contributed equally

Key words: factor VII light chain, tissue factor, lidamycin, NCI-H292, tumor-targeted therapy which requires a tumor target and a targeting molecule that can deliver and internalize a cytotoxic molecule. Our choice for a tumor target was tissue factor (TF), a transmembrane receptor overexpressed on many cancer cells. The TF levels of cancer cells are up to 1,000-fold greater than those of their normal counterparts. This overexpression is also observed in clinical samples of numerous types of human cancers, with just a few exceptions (e.g. renal cancer) (4).

Factor VII/VIIa (FVII), a ligand that binds to TF with exceptional affinity and specificity (5), is composed of a 20-kDa amino-terminal light chain and a 30-kDa carboxyterminal heavy chain, which are linked by a disulfide bond (6). The light chain binds to TF, and the heavy chain initiates the blood coagulation pathway $(7,8)$. Our choice for a targeting molecule was the light chain of human FVII (hlFVII) that is significantly smaller than the two-chain human FVII molecule, which should provide at least two therapeutic advantages: facilitating access of the targeted drug to a solid tumor (3) and preventing a blood clot that otherwise might occur when the two-chain hFVII molecule binds to TF (8).

The choice for a cytotoxic molecule was lidamycin (LDM), a member of the enediyne antibiotic family derived from Streptomyces globisporus C1027 (9,10), which is cytotoxic for cultured tumor cells and inhibits growth of a panel of human tumor xenografts $(11,12)$. The LDM molecule is composed of an 843-Da enediyne chromophore AE, which binds DNA in the minor groove and causes double-strand DNA breaks and tumor cell death, and a 10.5-kDa apoprotein LDP that forms a hydrophobic pocket protecting the AE chromophore (13-15). The AE and LDP domains of LDM can be dissociated in vitro and reconstituted with restored cytotoxic activity, which provides a two-step procedure containing DNA recombination and molecule reconstitution for synthesizing novel cytotoxic fusion proteins $(16,17)$.

Here we describe the construction of an energized fusion protein hlFVII-LDP-AE containing hlFVII as the targeting domain linked to LDM (LDP-AE) as the effector domain. The potential efficacy of hlFVII-LDP-AE for cancer therapy was tested in vitro by $\mathrm{MTT}$ and in vivo in a BALB/c nude mouse xenograft model of the human lung cancer line NCI-H292. The results demonstrate that hlFVII-LDP-AE strongly inhibits 
growth of the human lung cancer NCI-H292 cells in vitro and in vivo, suggesting that hlFVII-LDP-AE has potential clinical applications.

\section{Materials and methods}

Construction of expression plasmid. The diagrams of three recombinant proteins in this study are shown in Fig. 1A. The expression plasmids of the three recombinant proteins were constructed by conventional molecular cloning techniques. The DNA fragment encoding hlFVII (152 amino acids) (18) was cloned from the pCR4-TOPO-hFVII plasmid (FL25053, Fulengen Corp., China). The coding sequence for LDP was cloned from the plasmid pET-VH-LDP (19) constructed in our laboratory. The DNA fragment encoding mCherry was cloned from the pmCherry-N1 plasmid (Clontech). The expression vector is $\mathrm{pET}-19 \mathrm{~b}$ (Novagen).

Expression and purification of recombinant proteins. The recombinant plasmids were transformed into Rosetta-gami B(DE3)pLysS (Novagen) competent cells. A single colony was inoculated into $5 \mathrm{ml} \mathrm{LB}$ medium ( $\mathrm{pH} 7.5$ ) containing $100 \mu \mathrm{g} / \mathrm{ml}$ ampicillin, $34 \mu \mathrm{g} / \mathrm{ml}$ chloramphenicol, $15 \mu \mathrm{g} / \mathrm{ml}$ kanamycin and $12.5 \mu \mathrm{g} / \mathrm{ml}$ tetracycline and cultured overnight at $37^{\circ} \mathrm{C}$. The next day, 1 liter of culture medium was inoculated by overnight culture and incubated with shaking at $37^{\circ} \mathrm{C}$ until $\mathrm{A}_{600}$ was 0.6-1. Isopropyl-1-thio- $\beta$-D-galactopyranoside (IPTG) was added to the medium to a final concentration of $0.8 \mathrm{mM}$. After being induced for $6 \mathrm{~h}$ at $37^{\circ} \mathrm{C}$, the bacteria were lysed using pulse sonication followed by $60 \mathrm{~min}$ centrifugation at $48,400 \mathrm{x}$ g. His-tagged recombinant proteins were then purified by affinity chromatography (HisTrap HP, GE Healthcare) and ion exchange chromatography (HiTrap Q HP, GE Healthcare) according to the manufacturer's instructions.

Western blot analysis. The purified recombinant protein hlFVII-LDP was fractioned by a $12 \%$ SDS-PAGE gel, and then transferred to a polyvinylidene difluoride (PVDF) membrane (Millipore). The membrane was rinsed with PBST buffer (PBS, $0.1 \%$ Tween-20), blocked for $1 \mathrm{~h}$ in PBST containing 5\% (w/v) non-fat dried milk, and incubated with mouse anti-human FVII antibody (MAB2338, R\&D) for $1 \mathrm{~h}$. The membrane was washed with PBST and then incubated for $1 \mathrm{~h}$ with horseradish peroxidase (HRP)-conjugated anti-mouse IgG. The blot was visualized using an enhanced chemiluminescence (ECL) detection kit (Amersham Pharmacia Biotech).

Receptor-binding activity assay by ELISA. In brief, microtiter plates were coated with $50 \mu \mathrm{l} / \mathrm{well}$ of $20 \mu \mathrm{g} / \mathrm{ml}$ recombinant human TF (rhTF, R\&D Systems) or BSA as a control overnight at $4^{\circ} \mathrm{C}$. After washing, blocking and rewashing the plates, $30 \mu \mathrm{g} / \mathrm{ml}$ hlFVII-LDP diluted in blocking buffer $(25 \mathrm{mM}$ Tris, $150 \mathrm{mM} \mathrm{NaCl}, 5 \mathrm{mM} \mathrm{CaCl}, 0.1 \%$ Tween-20, $2 \%$ preimmune goat serum, $\mathrm{pH} 7.5$ ) were added to each well with $100 \mu \mathrm{l} /$ well and incubated for $60 \mathrm{~min}$ at $37^{\circ} \mathrm{C}$. After washing, $0.2 \mu \mathrm{g} / \mathrm{ml}$ mouse anti-human FVII antibody (MAB2338, R\&D Systems) diluted in $100 \mu \mathrm{l}$ blocking buffer was added to the wells and incubated for another $60 \mathrm{~min}$. Preimmune mouse serum was added as a negative control. The plates were washed again prior to incubation with $100 \mu \mathrm{l} /$ well of HRP-conjugated goat anti- mouse IgG antibody (ZF-0314, ZSGB-BIO Co., Ltd., Beijing, China) diluted 10,000-fold in blocking buffer. Finally, the plates were washed and the peroxidase reaction initiated by adding $100 \mu 1$ substrate/well $\left(0.02 \%\right.$ o-phenylenediamine, $0.01 \% \mathrm{H}_{2} \mathrm{O}_{2}$ ). The reaction was stopped after $10 \mathrm{~min}$, and the absorbance was read on a microplate reader (Biotech Instruments) at $492 \mathrm{~nm}$. All determinations were performed in triplicate.

Cell culture. The human NCI-H292 lung cancer, MCF-7 breast cancer and BJ human fibroblast cells were grown as monolayers in culture plates. Cells were cultured in either Dulbecco's modified Eagle's medium (DMEM) (NCI-H292 and BJ) or in Eagle's minimum essential medium (MCF-7) supplemented with $10 \%$ fetal bovine serum (FBS, Gibco) at $37^{\circ} \mathrm{C}$ in a humidified $5 \% \mathrm{CO}_{2}$ incubator.

Co-immunoprecipitation assay. hlFVII-LDP was added to medium containing the cultured human lung cancer line NCI-H292 to a final concentration of $0.5 \mu \mathrm{M}$ in 6-well plates. After culturing for $2 \mathrm{~h}$, cells were washed twice. Then, $1 \mathrm{ml}$ ice-cold PBS was added to the wells. Cells were scraped down and collected by centrifuging at $800 \mathrm{x} \mathrm{g}$ for $5 \mathrm{~min}$. Ice-cold lysis buffer of $300 \mu \mathrm{l}(20 \mathrm{mM}$ Tris- $\mathrm{HCl}, 150 \mathrm{mM} \mathrm{NaCl}, 10 \mathrm{mM}$ $\mathrm{KCl}, 0.5 \mathrm{mM}$ EDTA, $1.5 \mathrm{mM} \mathrm{MgCl} 2,0.5 \mathrm{mM}$ PMSF, $2 \mathrm{mM}$ DTT, $2.5 \mathrm{mM} \mathrm{CaCl}_{2}, 0.5 \%$ NP-40, $10 \%$ glycerol, pH 7.9) was add to the cells and incubated on ice. The cell suspensions were vortexed once every 2 min for 5 times. Lysates were centrifuged at $16,000 \times \mathrm{g}$ at $4^{\circ} \mathrm{C}$ for $5 \mathrm{~min}$. Subsequently, $200 \mu \mathrm{l}$ lysate supernatant and $800 \mu \mathrm{l}$ ice-cold lysis buffer were added to a $1.5 \mathrm{ml}$ Eppendorf tube. Then anti-human TF antibody (MAB2339, R\&D Systems) was added to the tube to a final concentration $10 \mu \mathrm{g} / \mathrm{ml}$. The mixture was incubated overnight at $4^{\circ} \mathrm{C}$. Complexes were collected with protein A agarose (Invitrogen), and the precipitates were washed three times with ice-cold lysis buffer. Then, proteins were released by boiling in sample buffer and analyzed by Western blotting using an anti-human FVII antibody as described above.

Internalization assay. The internalization of hIFVII-LDP assay was performed as described previously (20) with some modification. Cells $\left(1 \times 10^{5} /\right.$ well) were seeded in 6-well plates and cultured overnight. The next day, the medium was changed to protein transduction medium, which was prepared by mixing the recombinant fusion proteins at a final concentration of $150 \mathrm{nM}$ with normal medium supplemented with $3 \mathrm{mM} \mathrm{CaCl}_{2}$. Cells were incubated for another $12 \mathrm{~h}$, then were washed 3 times with PBS and fixed with 4\% paraformaldehyde (PFA) for $10 \mathrm{~min}$ at room temperature. After 3 washes, the cells were stained for $5 \mathrm{~min}$ at room temperature with 4',6-diamidino2-phenylindole (DAPI, Sigma). The cells were observed and photographed by fluorescence microscopy (Olympus, Japan).

Preparation of energized fusion protein hlFVII-LDP-AE. The energized fusion protein hIFVII-LDP-AE was prepared as previously described (21).

MTT assay. The 3-(4,5-dimethylthiazol-2-yl)-2,5-diphenyltetrazolium bromide (MTT) assays were used for measuring the cytotoxicity of energized fusion protein hlFVII-LDP-AE in vitro according to a previously described protocol (19). 


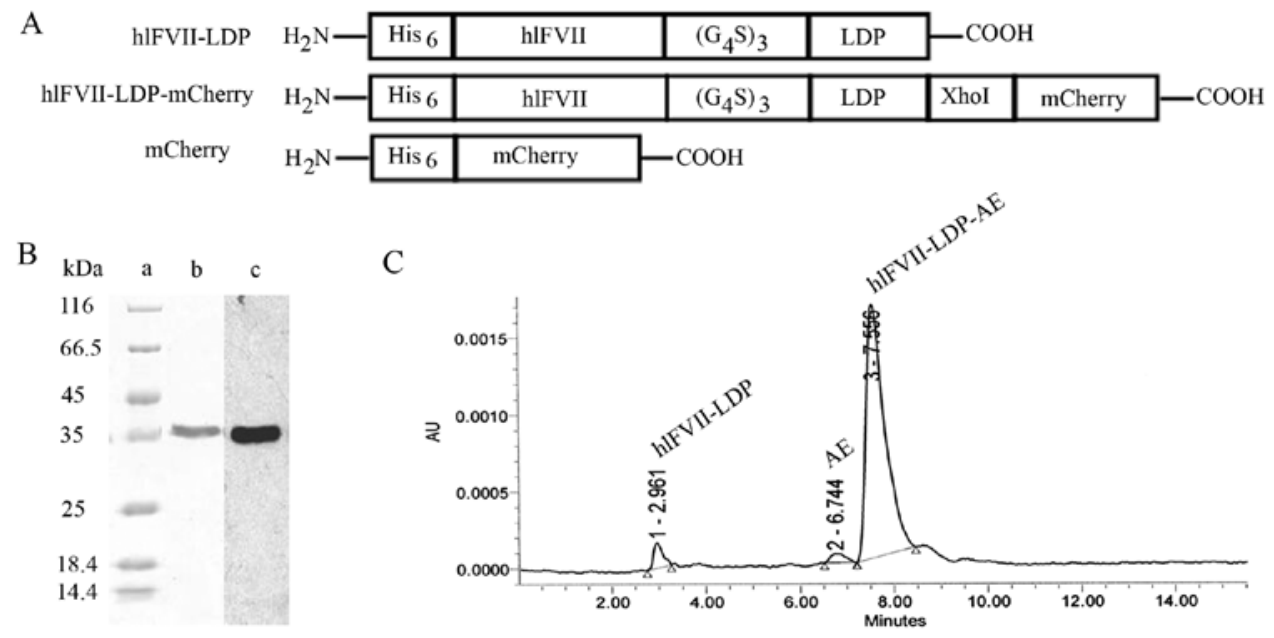

Figure 1. (A) Domain diagram of recombinant proteins hlFVII-LDP, hlFVII-LDP-mCherry and mCherry. His6, purifying tag composed of 6 histidines; hlFVII, the light chain of human factor VII; $\left(\mathrm{G}_{4} \mathrm{~S}\right)_{3}$, a flexible linker composed of triplicate GGGGS. LDP, the apoprotein of lidamycin; mCherry, a monomeric red fluorescent protein. (B) SDS-PAGE (lane b) and Western blotting (lane c) detection of hlFVII-LDP. (C) Analysis of energized fusion protein hlFVII-LDPAE determined by reverse-phase HPLC. AE, the chromophore of lidamycin.

Colony formation assay. Cells (500/well) were seeded in a 6-well plate and cultured in a humidified $5 \% \mathrm{CO}_{2}$ incubator for $24 \mathrm{~h}$. The next day, the medium was replaced with complete DMEM medium supplemented with $3 \mathrm{mM} \mathrm{CaCl}_{2}$ and $0.01 \mathrm{nM}$ LDM or hlFVII-LDP-AE. After culturing the cells for $2 \mathrm{~h}$, the medium was replaced with complete DMEM medium. The cells were cultured for another 10 days. Surviving colonies were stained with p-nitroblue tetrazolium chloride (NBT). The plate was scanned with a scanner (Perfection 4990 Photo, Epson).

Chromatin condensation assay. NCI-H292 cells ( 1 x 10\%/well) were seeded in a 6-well plate. The next day, the medium was replaced with fresh medium supplemented with $3 \mathrm{mM} \mathrm{CaCl}_{2}$ and hIFVII-LDP-AE $(0.19 \mathrm{nM})$ or LDM $(0.62 \mathrm{nM})$ at the $\mathrm{IC}_{50}$ concentration. After being incubated for $12 \mathrm{~h}$, the cells were washed with PBS for 3 times, and then were stained with the DNA-specific fluorescent dye Hoechst $33342(10 \mu \mathrm{g} / \mathrm{ml})$ (Sigma) for $10 \mathrm{~min}$ at $37^{\circ} \mathrm{C}$. The cells were washed with PBS again, then were observed and photographed with a fluorescence microscope (Olympus).

TUNEL assay. NCI-H292 cells were seeded in 24-well plates. After $24 \mathrm{~h}$, the medium was replaced with fresh medium supplemented with $3 \mathrm{mM} \mathrm{CaCl}_{2}$ and hIFVII-LDP-AE $(0.19 \mathrm{nM})$ or LDM $(0.62 \mathrm{nM})$ at the $\mathrm{IC}_{50}$ concentration and incubated at $37^{\circ} \mathrm{C}$. After $12 \mathrm{~h}$, the cells were washed with PBS for 3 times, fixed with $4 \%$ paraformaldehyde for $10 \mathrm{~min}$. TdT-mediated dUTP nick-end labeling (TUNEL) was performed by using DeadEnd $^{\mathrm{TM}}$ Colorimetric TUNEL System according to the manufacturer's instructions (Promega). Next, by microscopic analysis the cells were examined for cleavage of genomic DNA.

Efficacy studies in vivo. Female BALB/c nude mice (6-weekold) were purchased from the Institute of Laboratory Animal Sciences, Chinese Academy of Medical Sciences. The construction of the nude mice xenograft model of human lung cancer NCI-H292 cells was carried out as described by Guo et al (22). When the tumor size reached about $50 \mathrm{~mm}^{3}$, the mice were divided into 6 groups $(\mathrm{n}=8)$, and 5 groups were injected i.v. into the tail vein twice on Days 0 and 7 with LDM $(0.05 \mathrm{mg} / \mathrm{kg}$, tolerated dose), hlFVII-LDP $(0.6 \mathrm{mg} / \mathrm{kg})$ or hlFVII-LDP-AE ( 0.15 , 0.3 or $0.6 \mathrm{mg} / \mathrm{kg}$ ) in $200 \mu \mathrm{l}$ sterile saline. The control group was injected with $200 \mu 1$ sterile saline. To estimate the volume of developing tumors and the health condition of tumor-bearing mice, the exposed surface of the tumor was measured in two perpendicular directions, and the body weight was recorded every 3 days. The volume of a tumor was calculated as (width $\left.{ }^{2}\right)$ (length)/2. On Day 30, the tumors were removed from the mice, and the capacity of hlFVII-LDP-AE to inhibit tumor growth was assessed by a calculation following the formula 1 - (tumor volume $_{\text {treated }} /$ tumor volume control $) \times 100 \%$.

Inflammatory cytokine assay. BALB/c nude mice $(\mathrm{n}=6)$ were divided into 4 groups. One group was treated with hlFVIILDP-AE $(0.6 \mathrm{mg} / \mathrm{kg})$. The positive control group was treated with lipopolysaccharide (LPS, $0.25 \mathrm{mg} / \mathrm{kg}$ ). The negative control group was treated with $200 \mu \mathrm{l}$ sterile saline. Another control group was left untreated. Eighteen hours post-injection, blood was drawn from the mice and serum was separated as described by Dassie et al (23). Levels of the cytokines IL-1 $\beta$ and TNF- $\alpha$ were determined using ELISA kits (Bender MedSystems) according to manufacturer's instructions.

Statistical analysis. Data in all cases are expressed as mean \pm SE. Comparison of mean values between the different treatments was carried out using the two-way independentsample t-test with Microsoft Excel 2003 software. The level of significance was set at $\mathrm{P}<0.05$.

\section{Results}

Construction and preparation of fusion proteins. The diagrams of three recombinant proteins in this study are shown in Fig. 1A. hIFVII-LDP was correctly expression as shown by SDS-PAGE electrophoresis and Western blot analysis (Fig. 1B). Recombinant proteins hlFVII-LDP-mCherry and mCherry 
A

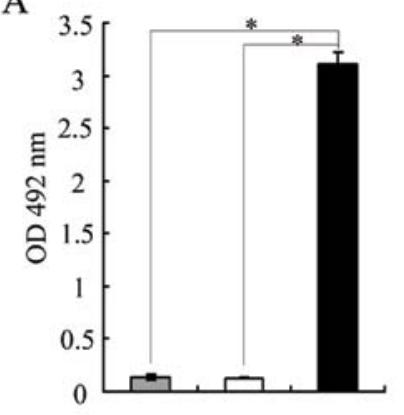

B

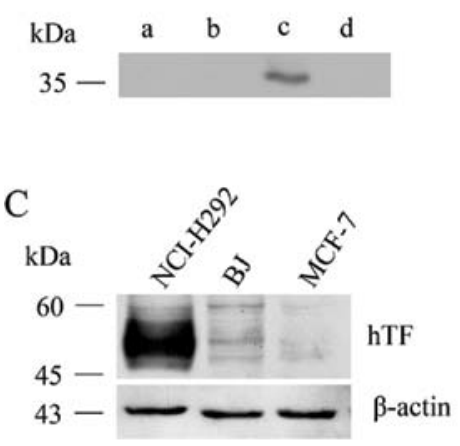

D
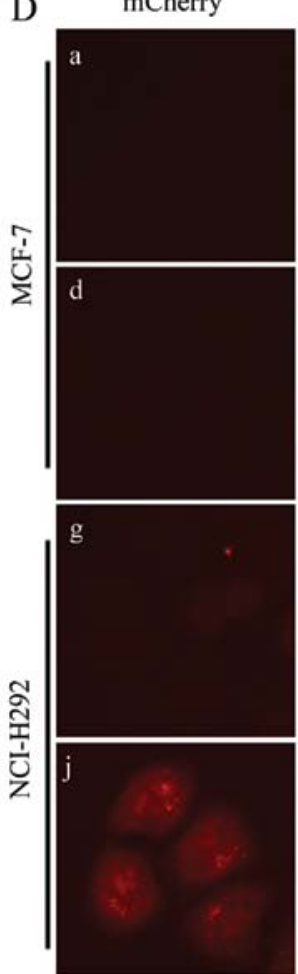

DAPI
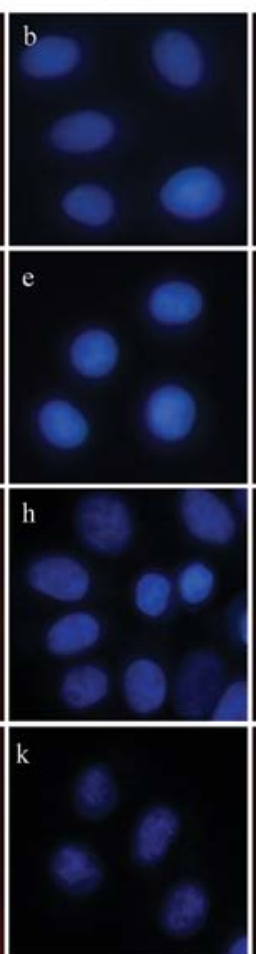

Merge
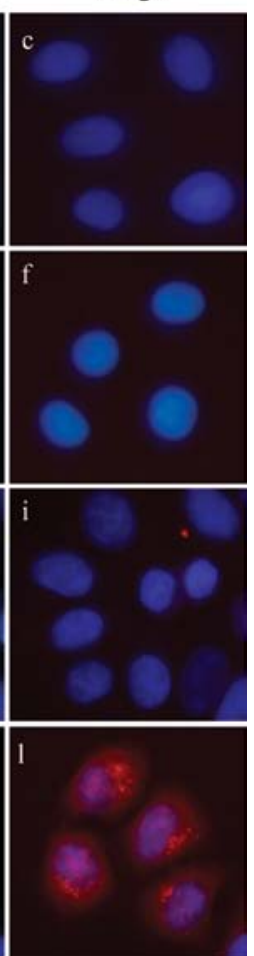

Figure 2. Binding and internalization of hlFVII-LDP. (A) Binding activity to rhTF was detected by ELISA. Gray bar, negative control, in which the coated rhTF was substituted with BSA. White bar, negative control, in which the primary antibody was substituted with preimmune serum. Black bar, the signal of hlFVIILDP binding to rhTF. t-test, ${ }^{*} \mathrm{P}<0.05$. (B) The binding specificity of hlFVII-LDP to TF expressed on NCI-H292 cells was verified by co-immunoprecipitation assay. Total protein extracted from NCI-H292 cells (lanes a, c and d) and MCF-7 cells (lane b) incubated with BSA (lane a) or hlFVII-LDP (lanes b-d) was incubated with either preimmune serum (lane d) or an anti-human TF monoclonal antibody (lanes a-c). The complexes formed were collected with protein A agarose and were analyzed by SDS-PAGE and Western blotting with anti-human FVII monoclonal antibody. (C) Expression of human TF on different cancer cell lines analyzed by Western blotting. hTF, human tissue factor. (D) Internalization assay of hlFVII-LDP by hlFVII-LDP-mCherry. Cells in (a-c) and (g-i) were treated with mCherry, and cells in (d-f) and (j-1) were treated with hlFVII-LDP-mCherry. Magnification, x200.

were identified by SDS-PAGE (data not shown) and by visible bioluminescence. Data from reverse-phase HPLC showed that the AE molecule integrated into hlFVII-LDP successfully, and the purity of hlFVII-LDP-AE was $92.78 \%$ (Fig. 1C).

Receptor-binding and internalization of hlFVII-LDP. The receptor-binding activity of hlFVII-LDP was analyzed by ELISA and co-immunoprecipitation assays. For ELISA, rhTF was used as the catching molecule. As shown in Fig. 2A, strong signals were detected for hlFVII-LDP (black bar), however, only weak signals were detected when BSA was used as the catching molecule (gray bar) or the first antibody was substituted with pre-immune serum (white bar). In the co-immunoprecipitation assay (Fig. 2B), hlFVIILDP appeared as a component of the immunoprecipitation complex with human TF expressed in NCI-H292 cells (lane c) that expresses human TF at a high level (Fig. 2C); however, preimmune serum (lane d) did not precipitate the hlFVIILDP protein, and no signal was observed in two other negative controls in which hlFVII-LDP was substituted with BSA (lane a) or the cells were substituted with the human breast cancer line MCF-7 (lane b) expressing low levels of TF (Fig. 2C).

To further confirm whether hlFVII-LDP could be internalized by TF-expressing tumor cells, we constructed the mCherry-tagged hlFVII-LDP (hlFVII-LDP-mCherry). The mCherry tag was used as a reporter. Free mCherry was used as a negative control. The red fluorescence of hlFVII-LDPmCherry was observed both on the membrane surface and in the cytoplasm of NCI-H292 cells (Fig. 2Dj-1). However, no red fluorescence could be detected in the mCherry group of the NCI-H292 cells (Fig. 2Dg-i) and in the MCF-7 cells incubated with mCherry (Fig. 2Da-c) or hlFVII-LDP-mCherry (Fig. 2Dd-f). These results show that hlFVII-LDP can bind to TF expressed on NCI-H292 cells specifically and can be internalized into the cytoplasm.

Efficacy of energized fusion protein hlFVII-LDP-AE in vitro. We measured the cytotoxicity of hlFVII-LDP-AE in two human cancer cell lines (NCI-H292 and MCF-7) and a normal human cell line (BJ) expressing different levels of human TF (Fig. 2C) by using the MTT assay. LDM was also tested for comparison. As shown by the half maximal inhibitory concentration $\left(\mathrm{IC}_{50}\right)$ values, hlFVII-LDP-AE (0.19 nM) was more potent than LDM (0.62 nM) for NCI-H292 cell lines that express high level human TF. However, the cytotoxicity of hlFVII-LDP-AE and LDM had no significant differences for MCF-7 and BJ cell lines that express low level human TF (Fig. 3A).

Colony formation assays using monolayers of NCI-H292 cells showed that the anti-tumor effects of hlFVII-LDP-AE (Fig. 3Bd) were much more potent than that of free LDM (Fig. 3Bb). However, hlFVII-LDP-AE (Fig. 3Bc), compared with LDM, did not show a more potent cytotoxicity to MCF-7 cells in the negative control (Fig. 3Ba). 

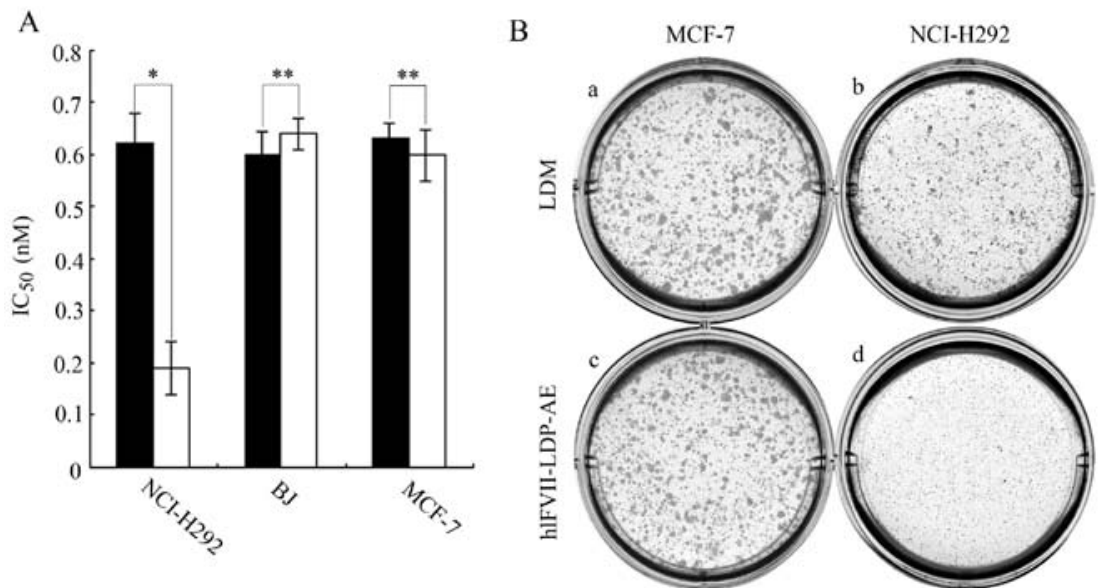

Figure 3. Anti-tumor effect of hlFVII-LDP-AE in vitro. (A) The IC $_{50}$ values of LDM and hlFVII-LDP-AE against NCI-H292, MCF-7 and BJ cells were measured by the MTT assay. t-test: " $\mathrm{P}<0.05 ;{ }^{* *} \mathrm{P}>0.05$. (B) Colony formation assay. NCI-H292 cells (b and d) and MCF-7 cells (a and c) in 6-well plates were treated with $0.01 \mathrm{nM}$ LDM ( $\mathrm{a}$ and $\mathrm{b}$ ) or hlFVII-LDP-AE ( $\mathrm{c}$ and d) for $2 \mathrm{~h}$ and the medium was replaced with new DMEM. The cells were cultured for another 10 days. After colonies were stained with NBT, the plates were scanned with a scanner.
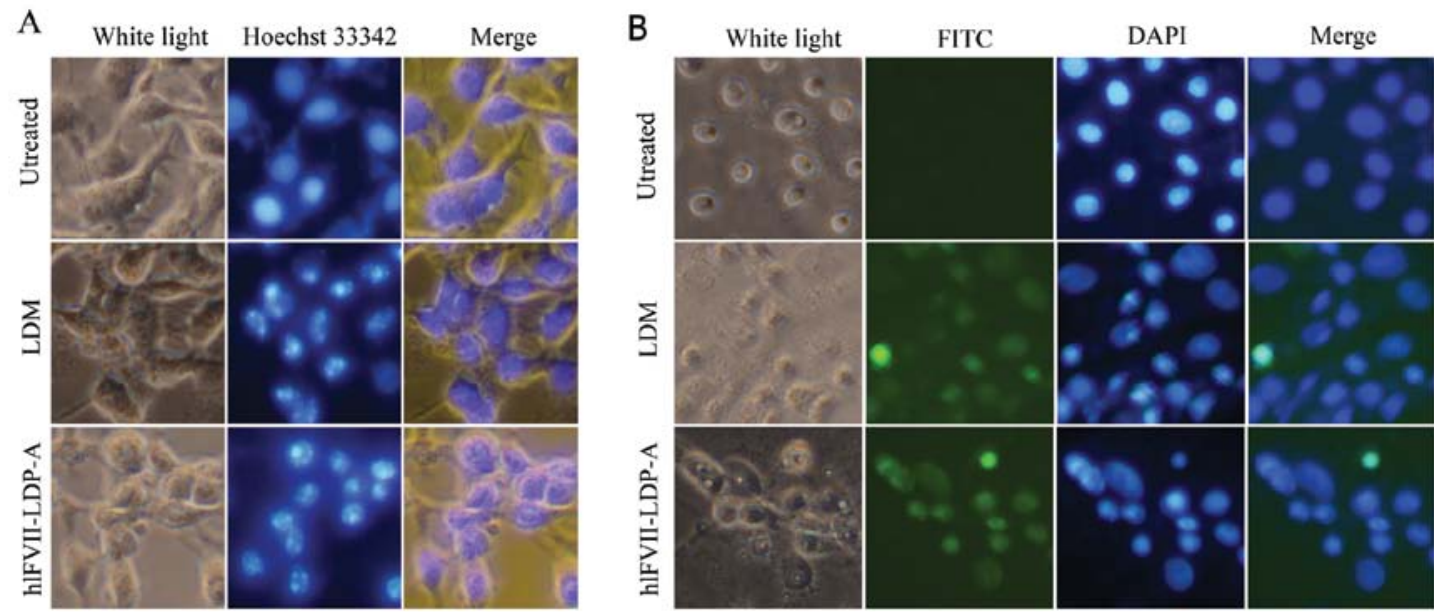

Figure 4. Chromatin condensation and cleavage of genomic DNA in human lung cancer NCI-H292 cells induced by hlFVII-LDP-AE determined by staining with the fluorescent dye Hoechst 33342 and the TUNEL assay, respectively. (A) Chromatin condensation assay. (B) TUNEL assay. Magnification, x200.

hlFVII-LDP-AE induced cancer cell death by causing chromatin condensation and cleavage of genomic DNA. As shown in Fig. 4A, chromatin condensations were clearly observed in the cells treated with hlFVII-LDP-AE or the free LDM. Further TUNEL assay showed that hlFVII-LDP-AE could induce cleavage of genomic DNA (Fig. 4B). These data suggest that the energized fusion protein hIFVII-LDP-AE causes tumor cell death through inducing chromatin condensation and cleavage of genomic DNA as the mechanism of LDM (24).

Therapeutic efficacy of energized fusion proteins hlFVII$L D P-A E$ in vivo. The antitumor effects of hlFVII-LDP-AE in vivo were tested in a nude mouse xenograft model of human lung cancer using the NCI-H292 cell line. The fusion protein hlFVII-LDP $(0.6 \mathrm{mg} / \mathrm{kg})$ showed $18.1 \%$ tumor growth inhibition (TGI); free LDM $(0.05 \mathrm{mg} / \mathrm{kg}$, a tolerated dose) showed $60.0 \%$ TGI; whereas, $0.15,0.3$ and $0.6 \mathrm{mg} / \mathrm{kg}$ hlFVII-LDP$\mathrm{AE}$ at greatly increased the antitumor efficacies with 65.2,75.0 and $85.2 \%$ TGI, respectively (Fig. 5). Furthermore, the TGI of hlFVII-LDP-AE at $0.6 \mathrm{mg} / \mathrm{kg}$ showed statistically significant differences compared with that of $\mathrm{LDM}$ at $0.05 \mathrm{mg} / \mathrm{kg}(\mathrm{P}<0.05)$ and that of hlFVII-LDP at $0.6 \mathrm{mg} / \mathrm{kg}(\mathrm{P}<0.001)$.

The safety of hlFVII-LDP-AE for applications in vivo. At the end of the experiment, weight loss resulting from the hlFVIILDP-AE treatment at different doses did not exceed $10 \%$ of the pretreatment weight (data not shown). Thus, the dosages of hlFVII-LDP-AE were tolerated (22).

To further test the safety of hlFVII-LDP-AE for in vivo applications, the levels of two important inflammatory cytokines, TNF- $\alpha$ and IL- $1 \beta$, in the serum of the mice treated with hlFVII-LDP-AE were assessed by ELISA $(25,26)$. LPS, an established immune stimulator (27-29), was included as a positive control. As shown in Fig. 6, LPS treatment triggered the robust increase of both TNF- $\alpha$ and IL- $1 \beta$ levels in serum. While no statistical differences were found between the hIFVII-LDP-AE-treated and the negative control group (sterile saline) or untreated group (Fig. 6). Together, these data suggest that hIFVII-LDP-AE does not trigger an innate immune response and is safe for in vivo applications. 


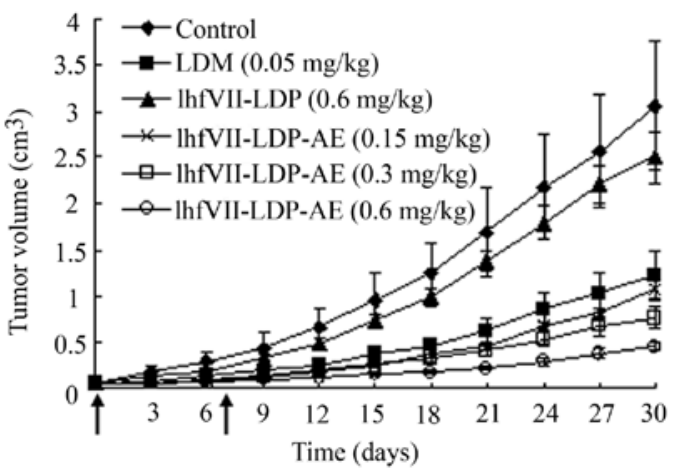

Figure 5. The growth inhibition of hlFVII-LDP-AE on NCI-H292 xenografts in nude mice. Arrows denote the days of injection. Tumor growth inhibition of hlFVII-LDP-AE at $0.6 \mathrm{mg} / \mathrm{kg}$ showed statistically significant differences compared with that of LDM at $0.05 \mathrm{mg} / \mathrm{kg}(\mathrm{P}<0.05)$ and that of hlFVII-LDP at $0.6 \mathrm{mg} / \mathrm{kg}(\mathrm{P}<0.001)$.
A

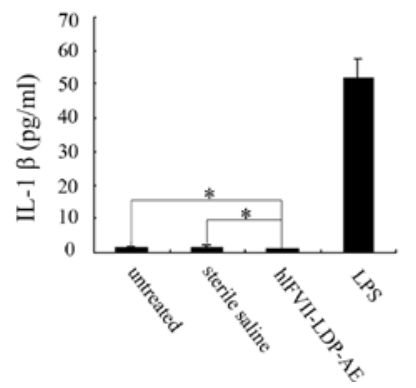

B

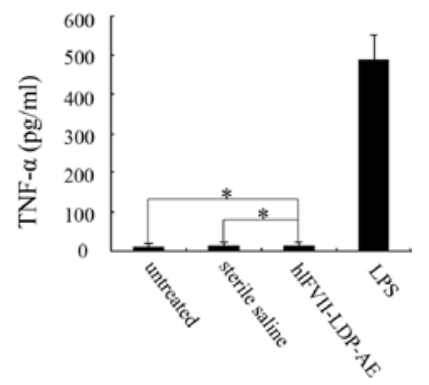

Figure 6. Assessment of potential immunostimulatory effects of hlFVIILDP-AE by ELISA. Serum from mice (untreated) and mice treated with either sterile saline, hlFVII-LDP-AE or LPS was screened for levels of the cytokines (A) IL-1 $\beta$ and (B) TNF- $\alpha$ using ELISA. t-test, ${ }^{*} \mathrm{P}>0.05$.

\section{Discussion}

In this study, we developed an effective and selective hlFVIItargeted LDM (hlFVII-LDP-AE) for lung cancer therapy. To the best of our knowledge, there are no published articles reporting that the light chain of FVII has been used as a targeting vehicle for the development of a targeted therapeutic agent.

Several TF-targeting therapeutic agents have been tested for the treatment of cancer and non-cancerous diseases. $\mathrm{Hu}$ et al (30) developed the first TF-targeting therapeutics, the antibody-like FVII-targeted Icon (FVII/IgG1 Fc), for cancer immunotherapy in 1999. In subsequent years, Icon immunotherapy was tested for the eradication of pathological neovasculature in other tumors $(5,31,32)$ and non-cancerous diseases such as wet macular dystrophy $(33,34)$ and human endometriosis (35). Hu et al (30) also developed two FVIItargeted photodynamic therapeutics for breast cancer by conjugating $\mathrm{Sn}(\mathrm{IV})$ chlorine e6 (SnCe6) or Verteporfin to FVII. In order to reduce the coagulation activity of FVIItargeted therapeutics, $\mathrm{Hu}$ and colleagues introduced a mutation (K341A) into the FVII protein $(5,30,32)$. Similarly, Shoji et al (36) reported the use of an active site-inactivated recombinant human FVIIa (FFRck-fVIIa) as a carrier for the targeted delivery of a potent synthetic curcumin analog (EF24) to TF-expressing tumor VECs and tumor cells. In conclusion,
FVII used in all the previous FVII-targeted therapeutics were prepared in eukaryotic cells, and their serine protease activity was inactivated by biological or chemical methods.

Here we report the development of a TF-targeting therapeutic, hlFVII-LDP-AE. As the targeting vehicle, the single-chain hlFVII molecule is significantly smaller than the parental two-chain human FVII molecule, which should provide two therapeutic advantages: facilitating access of the hlFVII-LDP-AE fusion protein to a solid tumor (3) and preventing a blood clot that otherwise might occur when the two-chained hFVII molecule binds to TF (8).

In this study, we show that the hlFVII-LDP fusion protein prepared in E. coli can bind to recombinant human TF (Fig. 2A) and human TF-expressing cancer cells (Fig. 2B). Furthermore, mCherry-tagged hlFVII-LDP can be internalized into cells by receptor-mediated endocytosis (Fig. 2D). In this experiment, we also observed that some of the mCherry-tagged fusion protein gathered near the nucleus (Fig. 2D). Why the fusion protein could be directed to the periphery of the nucleus needs further study. LDM induces cell death mainly by AE, which binds DNA in the minor groove and causes double-strand DNA breaks (13), and the fact that LDM is directed to cytoplasm and the periphery of the nucleus facilitates its function.

A possible caveat is that preventing blood clots might promote bleeding. However, no bleeding was detected in the mice treated with hlFVII-LDP-AE, which is consistent with similar results from another study in which mice were treated with an Icon molecule containing a two-chained hFVII targeting domain that had been mutated to prevent blood clotting (32).

In conclusion, we report for the first time an hlFVII-targeted LDM (hlFVII-LDP-AE) that selectively and effectively sacrificed cultured tumor cells in vitro and significantly inhibited the tumor growth of human lung cancer in vivo. As TF is expressed broadly in different types of tumors, including solid tumors $(5,30,32,37,38)$ and leukemia (39), hlFVII-LDP-AE has a broad therapeutic potential for lung and other cancers (39-41).

\section{Acknowledgements}

The Project was supported by the State Key Development Program for Basic Research of China (No. 2011CB504203), and 'Significant new drugs development' Science and Technology Major Projects of China (No. 2009ZX09103-698).

\section{References}

1. Yamanaka T, Okamoto T, Ichinose Y, Oda S and Maehara Y: Methodological aspects of current problems in target-based anticancer drug development. Int J Clin Oncol 11: 167-175, 2006.

2. Geney R, Chen J and Ojima I: Recent advances in the new generation taxane anticancer agents. Med Chem 1: 125-139, 2005.

3. Allen TM: Ligand-targeted therapeutics in anticancer therapy. Nat Rev Cancer 2: 750-763, 2002.

4. Rak J, Milsom C, Magnus N and Yu J: Tissue factor in tumour progression. Best Pract Res Clin Haematol 22: 71-83, 2009.

5. Hu Z and Garen A: Targeting tissue factor on tumor vascular endothelial cells and tumor cells for immunotherapy in mouse models of prostatic cancer. Proc Natl Acad Sci USA 98: 12180-12185, 2001.

6. Nemerson Y: Tissue factor and hemostasis. Blood 71: 1-8, 1988.

7. Ruf W, Kalnik MW, Lund-Hansen $T$ and Edgington TS: Characterization of factor VII association with tissue factor in solution. High and low affinity calcium binding sites in factor VII contribute to functionally distinct interactions. J Biol Chem 266: 15719-15725, 1991. 
8. Toomey JR, Smith KJ and Stafford DW: Localization of the human tissue factor recognition determinant of human factor VIIa. J Biol Chem 266: 19198-19202, 1991.

9. Hu JL, Xue YC, Xie MY, et al: A new macromolecular antitumor antibiotic, C-1027. I. Discovery, taxonomy of producing organism, fermentation and biological activity. J Antibiot (Tokyo) 41: 1575-1579, 1988.

10. Otani T, Minami Y, Marunaka T, Zhang R and Xie MY: A new macromolecular antitumor antibiotic, C-1027. II. Isolation and physico-chemical properties. J Antibiot (Tokyo) 41: 1580-1585, 1988.

11. Zhen YS, Ming XY, Yu B, Otani T, Saito H and Yamada Y: A new macromolecular antitumor antibiotic, C-1027. III. Antitumor activity. J Antibiot (Tokyo) 42: 1294-1298, 1989.

12. Xu YJ, Li DD and Zhen YS: Mode of action of C-1027, a new macromolecular antitumor antibiotic with highly potent cytotoxicity, on human hepatoma BEL-7402 cells. Cancer Chemother Pharmacol 27: 41-46, 1990.

13. Xu YJ, Zhen YS and Goldberg IH: C1027 chromophore, a potent new enediyne antitumor antibiotic, induces sequence-specific double-strand DNA cleavage. Biochemistry 33: 5947-5954, 1994

14. McHugh MM, Gawron LS, Matsui S and Beerman TA: The antitumor enediyne $\mathrm{C}-1027$ alters cell cycle progression and induces chromosomal aberrations and telomere dysfunction. Cancer Res 65: 5344-5351, 2005.

15. Jiang B, Li DD and Zhen YS: Induction of apoptosis by enediyne antitumor antibiotic C1027 in HL-60 human promyelocytic leukemia cells. Biochem Biophys Res Commun 208: 238-244, 1995.

16. Shao RG and Zhen YS: Enediyne anticancer antibiotic lidamycin: chemistry, biology and pharmacology. Anticancer Agents Med Chem 8: 123-131, 2008.

17. Xin C, Ye S, Ming Y, et al: Efficient inhibition of B-cell lymphoma xenografts with a novel recombinant fusion protein anti-CD20Fab-LDM. Gene Ther 17: 1234-1243, 2010.

18. Hagen FS, Gray CL, O'Hara P, et al: Characterization of a cDNA coding for human factor VII. Proc Natl Acad Sci USA 83 2412-2416, 1986.

19. Miao QF, Liu XY, Shang BY, Ouyang ZG and Zhen YS: An enediyne-energized single-domain antibody-containing fusion protein shows potent antitumor activity. Anticancer Drugs 18: 127-137, 2007.

20. Zhou H, Wu S, Joo JY, et al: Generation of induced pluripotent stem cells using recombinant proteins. Cell Stem Cell 4: 381-384, 2009.

21. Zhong G, Zhang S, Li Y, et al: A tandem scFv-based fusion protein and its enediyne-energized analogue show intensified therapeutic efficacy against lung carcinoma xenograft in athymic mice. Cancer Lett 295: 124-133, 2010.

22. Guo XF, Zhu XF, Shang Y, Zhang SH and Zhen YS: A bispecific enediyne-energized fusion protein containing ligand-based and antibody-based oligopeptides against epidermal growth factor receptor and human epidermal growth factor receptor 2 shows potent antitumor activity. Clin Cancer Res 16: 2085-2094, 2010.

23. Dassie JP, Liu XY, Thomas GS, et al: Systemic administration of optimized aptamer-siRNA chimeras promotes regression of PSMA-expressing tumors. Nat Biotechnol 27: 839-849, 2009.

24. Wang Z: Non-caspase-mediated apoptosis contributes to the potent cytotoxicity of the enediyne antibiotic lidamycin toward human tumor cells. Biochem Pharmacol 65: 1767-1775, 2003.
25. Onda M, Willingham M, Wang QC, et al: Inhibition of TNF-alpha produced by Kupffer cells protects against the nonspecific liver toxicity of immunotoxin anti-Tac(Fv)-PE38, LMB-2. J Immunol 165: 7150-7156, 2000

26. Vallera DA, Seo SY, Panoskaltsis-Mortari A, Griffin JD and Blazar BR: Targeting myeloid leukemia with a DT(390)-mIL-3 fusion immunotoxin: ex vivo and in vivo studies in mice. Protein Eng 12: 779-785, 1999.

27. Stewart I, Schluter PJ and Shaw GR: Cyanobacterial lipopolysaccharides and human health - a review. Environ Health 5: 7, 2006.

28. Joseph WR, Cao Z, Mountjoy KG, Marshall ES, Baguley BC and Ching LM: Stimulation of tumors to synthesize tumor necrosis factor-alpha in situ using 5,6-dimethylxanthenone-4-acetic acid: a novel approach to cancer therapy. Cancer Res 59: 633-638, 1999.

29. Rao P, Hayden MS, Long M, et al: IkappaBbeta acts to inhibit and activate gene expression during the inflammatory response. Nature 466: 1115-1119, 2010.

30. Hu Z, Sun Y and Garen A: Targeting tumor vasculature endothelial cells and tumor cells for immunotherapy of human melanoma in a mouse xenograft model. Proc Natl Acad Sci USA 96: 8161-8166, 1999

31. Tang Y, Borgstrom P, Maynard J, et al: Mapping of angiogenic markers for targeting of vectors to tumor vascular endothelial cells. Cancer Gene Ther 14: 346-353, 2007.

32. Hu Z and Garen A: Intratumoral injection of adenoviral vectors encoding tumor-targeted immunoconjugates for cancer immunotherapy. Proc Natl Acad Sci USA 97: 9221-9225, 2000.

33. Tezel TH, Bodek E, Sonmez K, et al: Targeting tissue factor for immunotherapy of choroidal neovascularization by intravitreal delivery of factor VII-Fc chimeric antibody. Ocul Immunol Inflamm 15: 3-10, 2007

34. Bora PS, Hu Z, Tezel TH, et al: Immunotherapy for choroidal neovascularization in a laser-induced mouse model simulating exudative (wet) macular degeneration. Proc Natl Acad Sci USA 100: 2679-2684, 2003.

35. Krikun G, Hu Z, Osteen K, et al: The immunoconjugate 'icon' targets aberrantly expressed endothelial tissue factor causing regression of endometriosis. Am J Pathol 176: 1050-1056, 2010.

36. Shoji M, Sun A, Kisiel W, et al: Targeting tissue factor-expressing tumor angiogenesis and tumors with EF24 conjugated to factor VIIa. J Drug Target 16: 185-197, 2008.

37. Contrino J, Hair G, Kreutzer DL and Rickles FR: In situ detection of tissue factor in vascular endothelial cells: correlation with the malignant phenotype of human breast disease. Nat Med 2: 209-215, 1996.

38. Callander NS, Varki N and Rao LV: Immunohistochemical identification of tissue factor in solid tumors. Cancer 70: 1194-1201, 1992.

39. Bauer KA, Conway EM, Bach R, Konigsberg WH, Griffin JD and Demetri G: Tissue factor gene expression in acute myeloblastic leukemia. Thromb Res 56: 425-430, 1989.

40. Hair GA, Padula S, Zeff R, et al: Tissue factor expression in human leukemic cells. Leuk Res 20: 1-11, 1996.

41. Andoh K, Kubota T, Takada M, Tanaka H, Kobayashi N and Maekawa T: Tissue factor activity in leukemia cells. Special reference to disseminated intravascular coagulation. Cancer 59: 748-754, 1987. 